\title{
REACCIONES DEL HUESO FRENTE AL ESTRES: ESTUDIO RADIOLOGICO
}

\author{
Drs. Sara Muñoz Ch, Paola Paolinelli G.
}

Servicio de Diagnóstico por Imágenes. Clínica Las Condes

\begin{abstract}
The musculoskeletal lesions related to acute or chronic stress are multiples and common clinical conditions. This article reviews the imaging findings and physiopathology in these conditions.
\end{abstract}

Key words: Bone lesion, Muscle lesion, Stress.

Resumen: Las reacciones del sistema músculoesquelético frente al estrés agudo o crónico son variadas y pueden producir lesiones de distinta naturaleza. Este artículo revisa los hallazgos imagenológicos y discute la fisiopatología de estas lesiones.

Palabras claves: Estrés, Lesión muscular, Lesión ósea.

\section{Introducción}

El sistema músculo esquelético está formado por huesos, articulaciones, ligamentos, músculos y tendones. Su arquitectura o forma de ensamblaje varía según la edad y el segmento corporal. Es, por lo tanto, un error considerar a cada una de estas estructuras por separado o aisladamente ya que conforman un sistema único. Las reacciones frente al estrés son por lo tanto una reacción de todas ellas, comprometiendo no sólo al hueso sino que al sistema completo.

Existe una constelación de lesiones músculoesqueléticas que se producen frente al estrés agudo y crónico. Su diagnóstico imagenológico se hace sobre la base de la distribución y localización de las alteraciones.

\section{Biomecánica esquelética}

Desde el punto de vista médico, una fractura se define como una interrupción en la continuidad de un hueso. Mecánicamente se define como una

Muñoz S, Paolinelli P. Reacciones del hueso frente al estrés: Estudio radiológico. Rev Chil Radiol 2005; 11:81-90.

Correspondencia: Dra. Sara Muñoz Ch.

Departamento de Radiología, Clínica Las Condes.

Lo Fontecilla 441, Las Condes. Santiago de Chile.

E-mail: sara.munoz@entelchile.net falla estructural cuando éste es sometido a una fuerza que sobrepasa su capacidad de resistencia.

Una fuerza aplicada sobre un objeto y que lo cambia o distorsiona es denominada estrés. La distorsión se llama tensión y se mide como cambio en la dimensión ya sea de longitud, ancho o angulación relativo al estado original.

Estrés se define como carga por unidad de área y es la fuerza o carga absoluta aplicada al hueso que se puede ejercer por acción muscular o del soporte a la carga. Esta puede ser aplicada como una fuerza compresiva o de tensión.

Inicialmente al aplicar un estrés la tensión resultante es directamente proporcional a la fuerza aplicada produciéndose una deformación elástica. En esta etapa los cambios son reversibles y, una vez retirada la fuerza, el objeto vuelve a su morfología inicial sin quedar deformación residual. La relación estrés-tensión constituye el coeficiente elástico que corresponde a una medida de la calidad o rigidez. A mayor estrés requerido para deformar un objeto, mayor grado de rigidez. Al aumentar la fuerza se alcanza el estrés elástico límite y la tensión elástica límite del objeto. En este punto la deformación ya no es proporcional al estrés y una leve alteración de éste resulta en un alto grado de tensión o deformidad del hueso. Si se suspende la fuerza, el objeto es incapaz de volver a su forma inicial y queda una deformidad residual. Esto constituye la deformación plástica. Si la fuerza continúa se llega a un punto en que el objeto se rompe o fractura. Este es el punto de falla (Figura 1).

Existen diferentes lesiones en el sistema músculo-esquelético cuyas formas de presentación dependen del tipo de fuerza o estrés (tensional, compresiva, cizallamiento, angulación o rotación) a la que las estructuras son sometidas y, por otra parte, al tiempo durante el cual actúa.

Las reacciones y fracturas de estrés representan un espectro de lesiones óseas y de tejidos blandos que ocurren en respuesta a fuerzas mecánicas. Las reacciones al estrés son lesiones que ocurren antes del punto de falla, que responden a 
estrés agudo, crónico o repetitivo. La fractura representa la respuesta más grave del hueso frente a cualquiera de estos tipos de estrés.
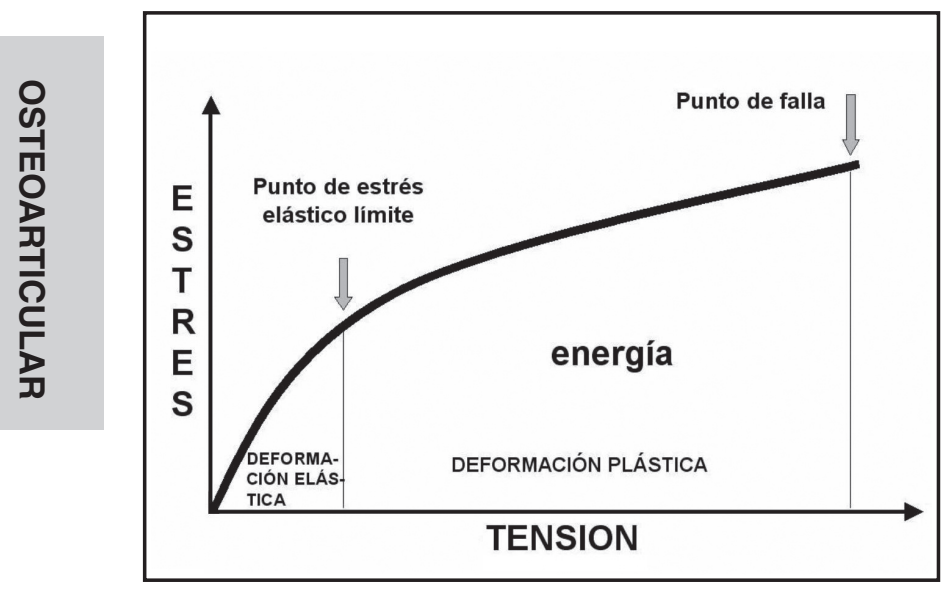

Figura 1. Curva de estrés versus tensión que se aplica a todos los materiales para conocer sus características de resistencia y rigidez.

\section{Lesiones y fracturas de estrés}

Con fines didácticos se clasifican en: A. Lesiones traumáticas agudas que a su vez las podemos subdividir en: 1) Por impactación: contusión ósea; fractura por hundimiento; fractura osteocondral y fractura completa. 2) Por avulsión: fracturas por esta causa. B. Lesiones producidas por trauma repetido dentro de las cuales consideraremos 1) Lesiones avulsivas crónicas: en la pierna (Shint splint); en el muslo (Thigt splint); y en el pubis (Osteítis del pubis). 2) Fracturas por fatiga.

\section{A1. Lesiones por impactación}

La resonancia magnética $(\mathrm{RM})$ es extremadamente sensible para detectar un grupo heterogéneo de lesiones post-traumáticas agudas que no tienen representación en la radiografía simple $(\mathrm{Rx})$. Algunas comprometen claramente las superficies articulares y son consideradas como fracturas osteocondrales, mientras que otras se localizan a distancia de ésta(6). Se supone que representan una gama de alteraciones, en que el aspecto imagenológico depende del mecanismo y magnitud de la lesión. En un extremo de este espectro está la contusión ósea y en el otro la fractura franca o completa que puede o no comprometer la superficie ósea y el cartílago.

Las contusiones óseas se identifican frecuentemente en RM después de un traumatismo músculoesquelético (Figura 2), que puede resultar de un golpe directo sobre el hueso, por fuerzas compresivas de huesos adyacentes o por fuerzas de tracción como ocurre durante una lesión por avulsión. Estas áreas de contusión representan focos de hemorragia, edema o hiperemia secundaria a microfractura trabecular. Pueden ser sintomáticas por varias semanas.

En RM la alteración de señal de la médula ósea es autolimitada y puede prolongarse hasta 12 a 14 semanas, siendo lo más común que permanezca durante 6 semanas. Se resuelve en forma centrípeta, es decir, como un cubo de hielo que se derrite. Son lesiones geográficas, mal delimitadas, con márgenes irregulares.

Existen diferentes patrones de contusión que muchas veces permiten inferir el mecanismo de lesión. Tal vez uno de los ejemplos más clásicos lo constituyen los focos de contusión ósea que pueden acompañar a una rotura del ligamento cruzado anterior en la rodilla, especialmente cuando el mecanismo es estrés en valgo ${ }^{(6)}$ (Figura 3 ). En estos casos encontramos focos de contusión en la región posterior del platillo tibial externo y en el cóndilo femoral externo. Si el estrés aumenta podemos encontrar, además, una fractura por hundimiento en el cóndilo femoral externo (Figura 4), similar a la fractura de Hill Sachs (Figura 5) que ocurre en una luxación anterior de hombro. Si la fuerza es aun mayor podemos encontrar una lesión osteocondral (Figura 6) o una fractura completa (Figura 7).

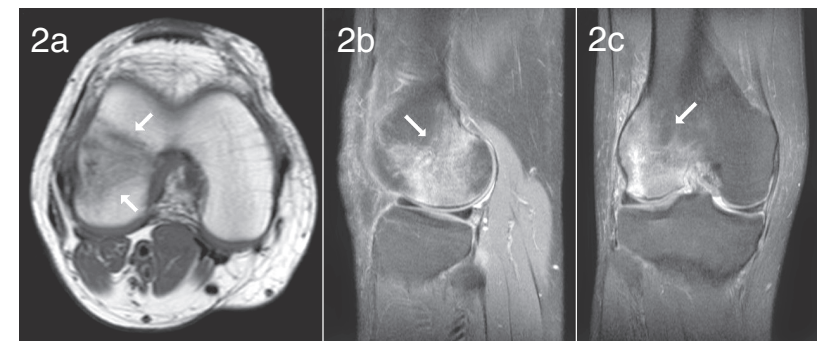

Figura 2 a-c. RM de paciente con historia de traumatismo de rodilla y dolor. a) Corte Axial en T1. b,c) Secuencias DPFS; corte sagital b) y Coronal c) Se demuestra edema óseo en el cóndilo femoral externo, geográfico, de margen irregular, compatible con contusión ósea (flechas).

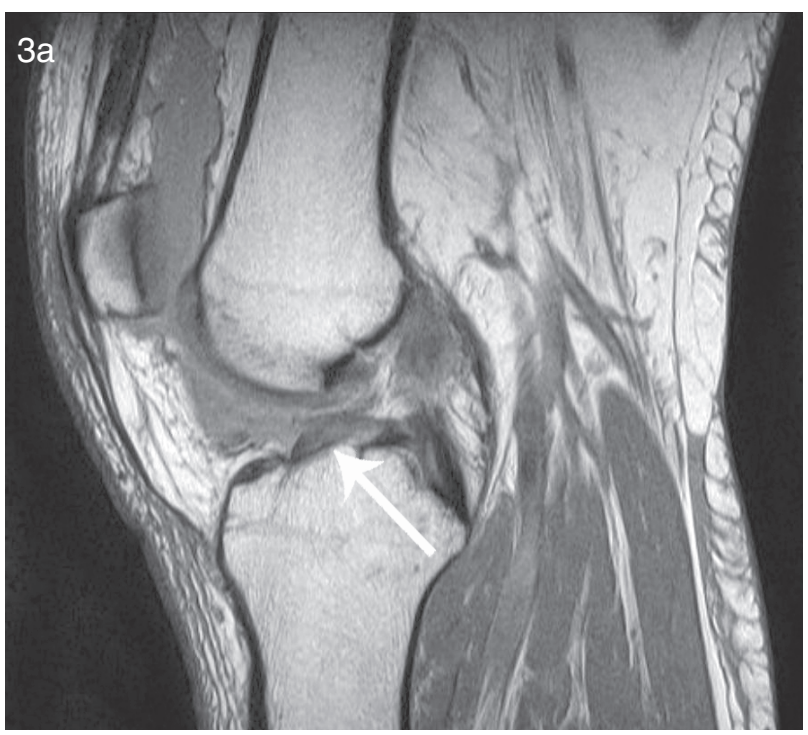

Figura 3 a. 


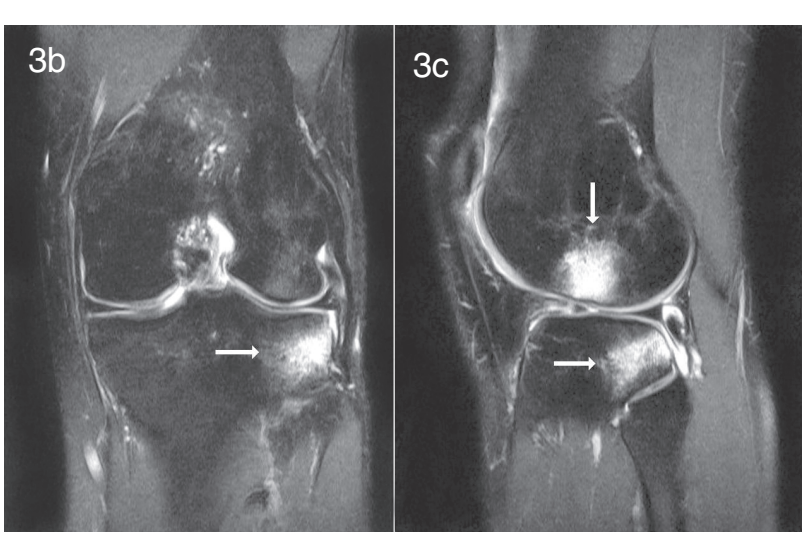

Figura 3 a-c. Paciente que sufre estrés en valgo y rotación de la rodilla: a) RM cortes sagital DP. b) DPFS coronal. c) Sagital. Muestran rotura del ligamento cruzado anterior (flecha en a) y focos característicos de contusión ósea en cóndilo femoral externo y aspecto posterior del platillo tibial externo (flechas en $b$ y $c$ ).

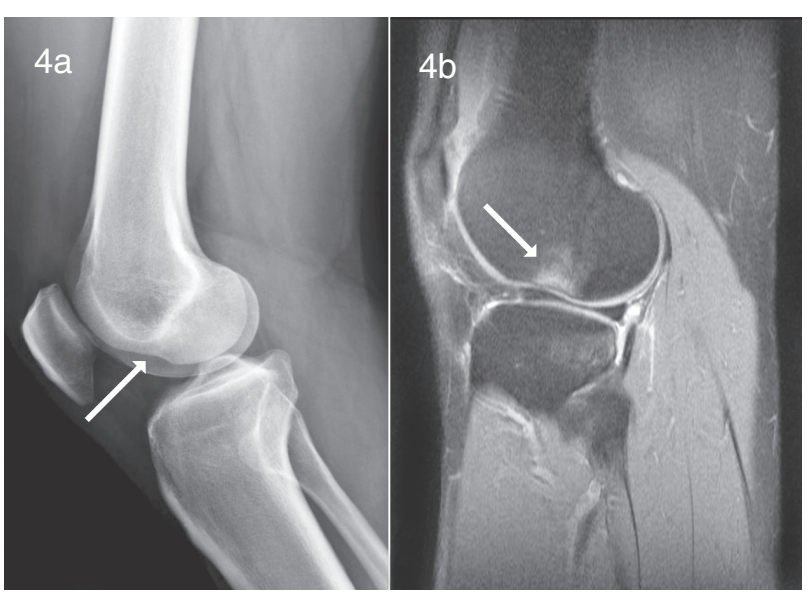

Figura 4 a, b. Paciente que sufre estrés en valgo y rotación de la rodilla: a) $R x$ simple lateral. b) $R M$ corte sagital secuencia DPFS. Muestran fractura por hundimiento en cóndilo femoral externo y edema óseo por contusión (flechas).

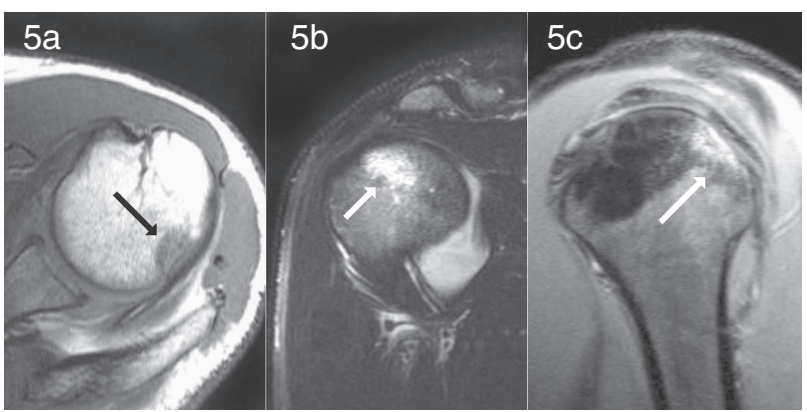

Figura 5 a-c. Paciente con evento de luxación anterior de hombro: a) RM cortes sagital oblicuo T1. b) Axial T2. c) Coronal DPFS. Muestran fractura por hundimiento (flechas) en el aspecto póstero-superior de la cabeza humeral (Fractura de Hill Sachs).
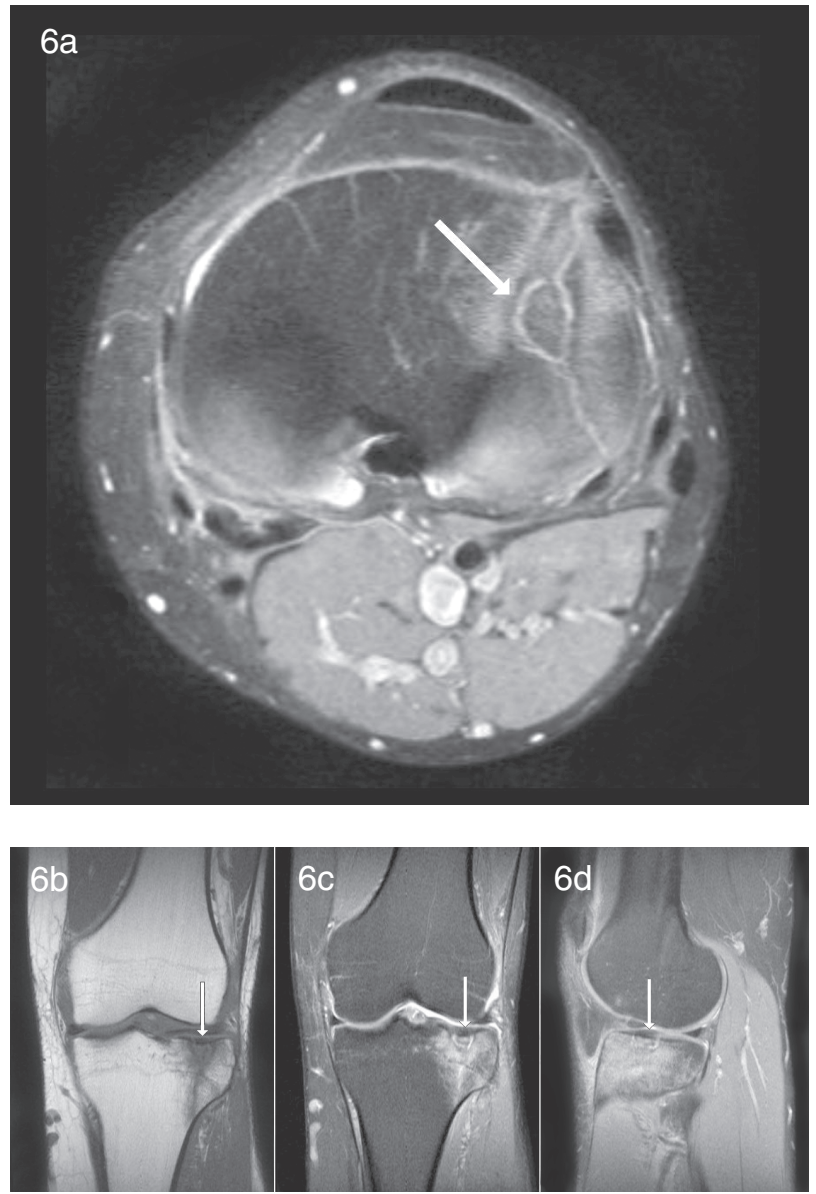

Figura 6 a-d. Paciente que sufre traumatismo de rodilla: a) RM en cortes axial DPFS. b) Coronal T1. c) DPFS coronal. d) Sagital. Muestran fractura de platillo tibial externo con un fragmento osteocondral (flechas) y edema.

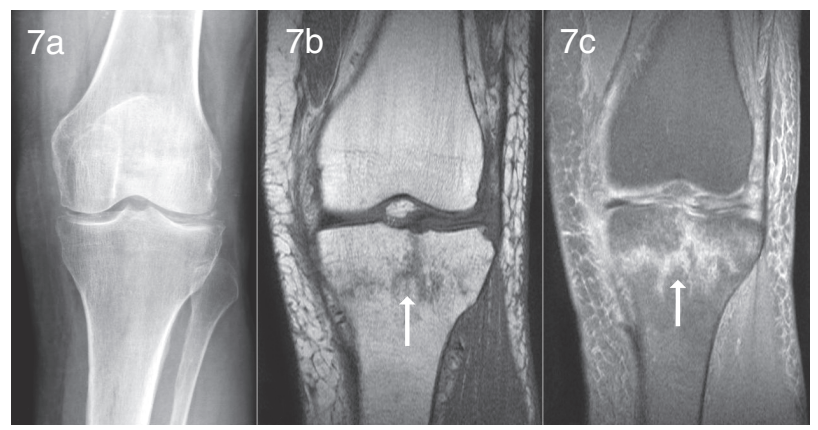

Figura 7 a-c. Paciente adulta mayor con dolor de rodilla después de trauma leve: a) $R x$ simple $A P$ de rodilla, muestra sólo osteopenia. b) RM Cortes coronales en T1 c) DPFS. Demuestran una fractura del platillo tibial no desplazada (flechas).

\section{A2. Fracturas por avulsión}

Ocurren por una fuerza tensil excesiva sobre un hueso o cartílago que arranca un fragmento óseo, por la acción de un ligamento, del tendón o de la cápsula articular como resultado de contracción muscular excéntrica extrema y desbalanceada. Pueden ocurrir a cualquier edad 
pero son más frecuentes en púberes y adolescentes por el desbalance entre la fuerza muscular y la vulnerabilidad inherente de las apófisis ${ }^{(1,4)}$.

Ocurren en diferentes localizaciones pero son más comunes en la pelvis a nivel de espinas ilíacas y pubis ${ }^{(1)}$. Se estudian, por lo general, con $\mathrm{Rx} \operatorname{simple}^{(4)}$ (Figura 8), que es suficiente para el diagnóstico en la mayoría de los casos. Se requiere un acabado conocimiento de la anatomía para identificar fácilmente los sitios de inserción de tendones y ligamentos. El Ultrasonido (US) también es útil para el diagnóstico (Figura 9,10), estando especialmente indicado en casos de Rx simple dudosa (Figura 9,10).

En RM el fragmento avulsionado puede ser difícil de demostrar, ya sea por lo pequeño o por el edema que se produce en los tejidos blandos adyacentes que lo pueden enmascarar. El edema óseo que se produce en el nicho del arrancamiento es mucho menor que el que se ve en lesiones por impactación (Figura 11).

En el estudio radiológico las lesiones agudas son demostradas como un fragmento óseo avulsionado, mientras que las subagudas pueden tener una apariencia radiológica que puede incluir áreas mixtas de lisis con esclerosis, simulando una lesión agresiva. Las lesiones crónicas pueden estar asociadas a masas protuberantes de hueso y ser confundidas con neoplasia o infección (Figura 12). Por ello resulta fundamental conocer los antecedentes clínicos del paciente y trabajar en fluida comunicación con el equipo médico.

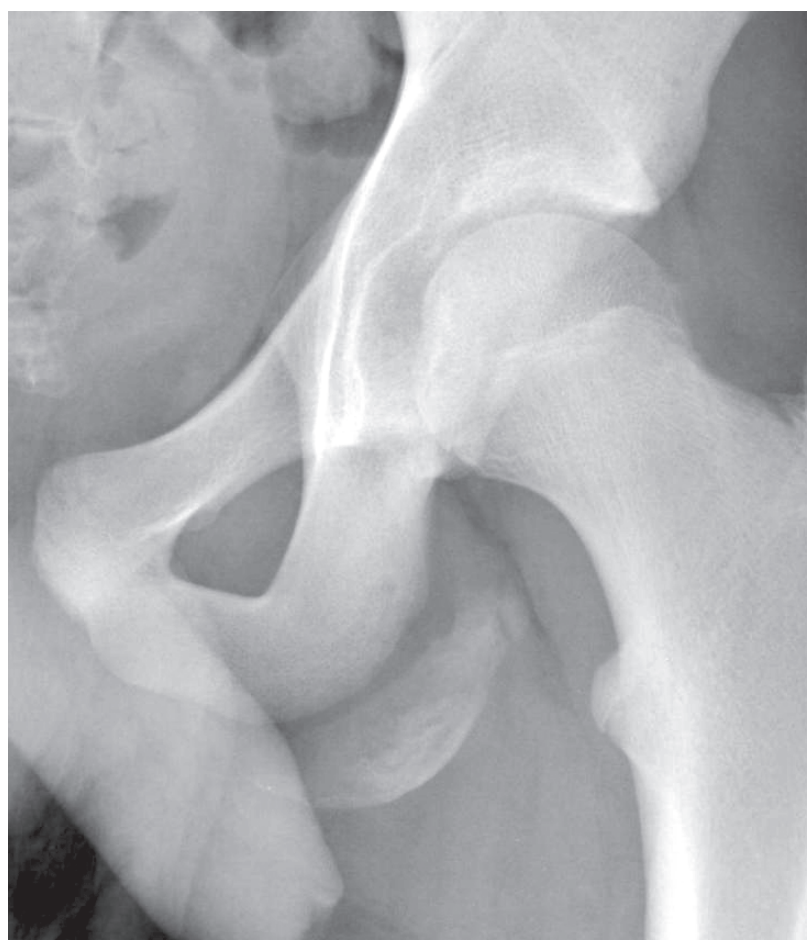

Figura 8. Adolescente con dolor glúteo izquierdo después de ejercicio brusco. $R x$ simple AP de pelvis localizada del isquión izquierdo, demostrando arrancamiento óseo.

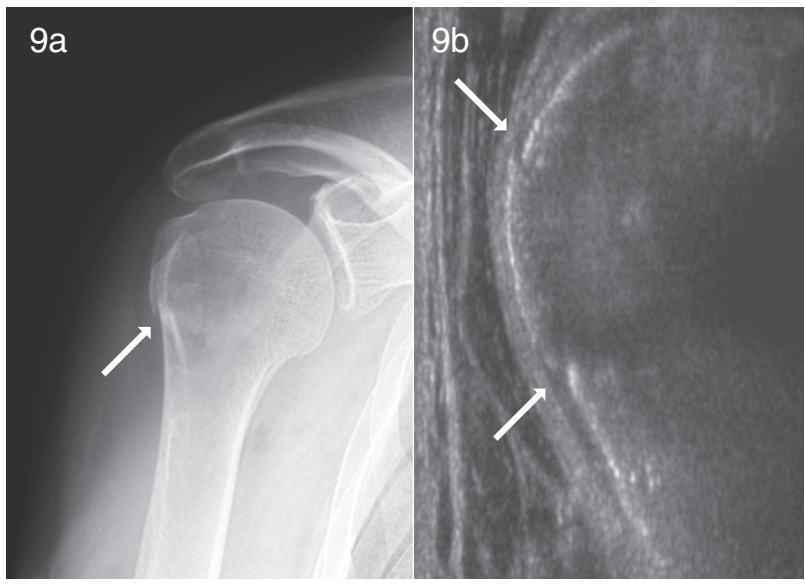

Figura 9 a-b. Paciente con traumatismo de hombro: a) $R x$ simple AP de hombro que muestra un pequeño resalte óseo a nivel de troquiter (flecha). b) US demostrando claramente un resalte cortical compatible con fractura (flecha).

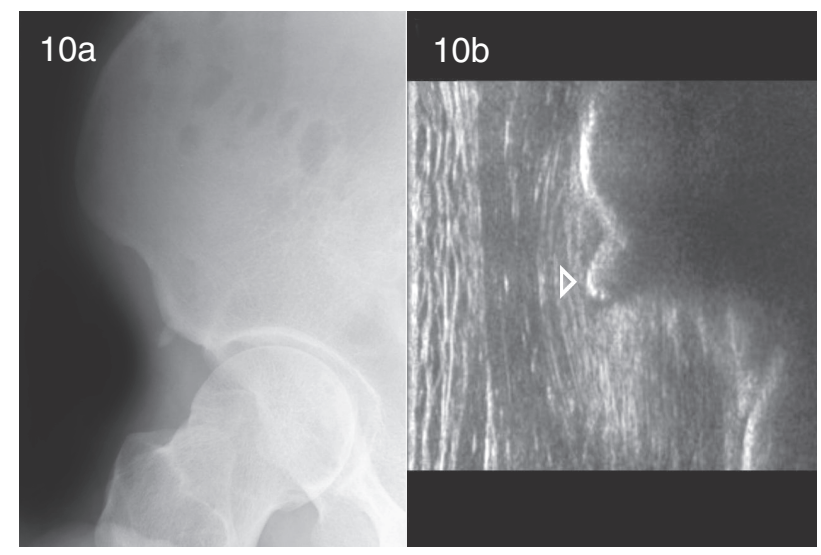

Figura 10 a, b. Adolescente con dolor en cadera derecha posterior a traumatismo: a) $R x$ simple AP localizada de cadera muestra un cuerpo óseo adyacente a la espina ilíaca antero-inferior. b) La US confirma la presencia del cuerpo óseo en el tendón del recto femoral (punta de flecha).

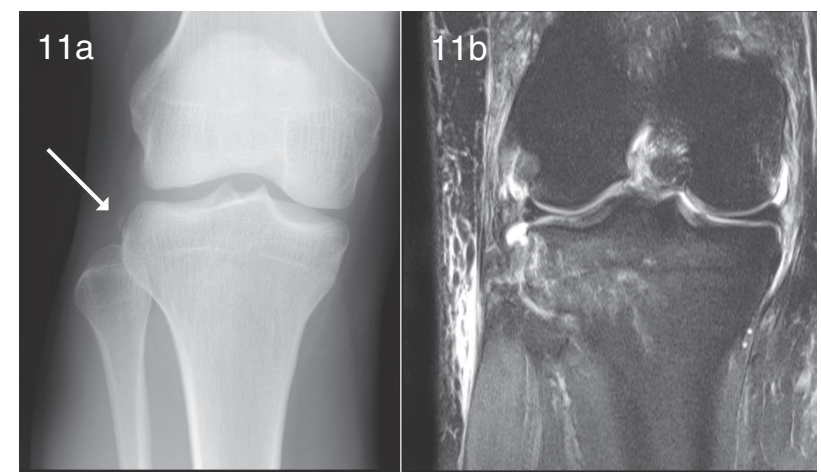

Figura 11 a-b. Paciente que sufre traumatismo de rodilla con rotura del ligamento cruzado anterior: a) $R x$ simple $A P$ de rodilla que muestra un pequeño cuerpo óseo adyacente platillo tibial externo (flecha), correspondiente a fractura de Segond. b) RM en corte coronal DPFS demostrando edema óseo. 


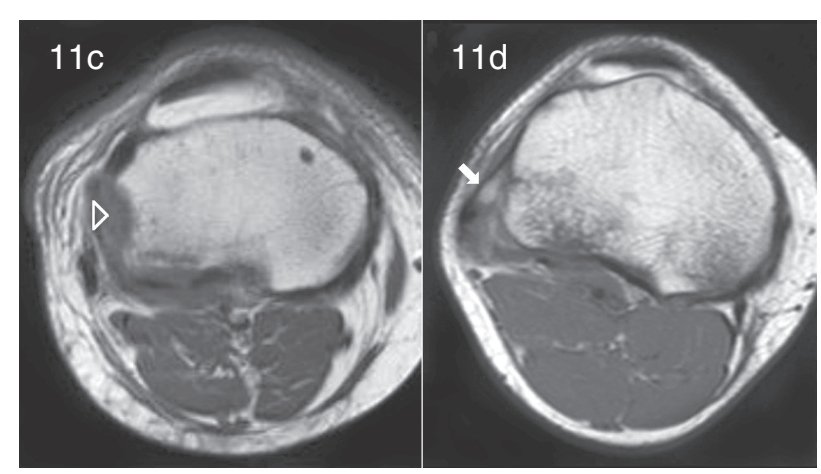

Figura 11 c-d. Cortes axiales en T1 demuestran edema óseo, un nicho en el platillo tibial (cabeza de flecha en c) y un fragmento óseo (flecha corta gruesa en d).

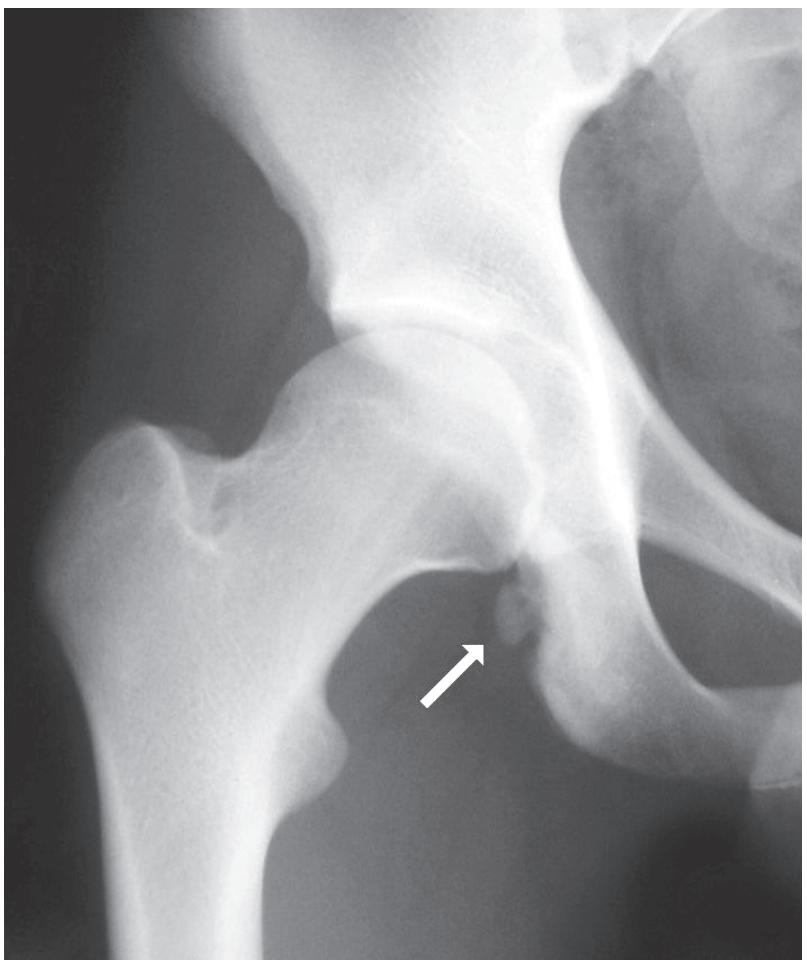

Figura 12. Paciente con antecedente de arrancamiento óseo. Rx simple AP de cadera derecha localizada, muestra proliferación ósea que de acuerdo al antecedente correspondería a arrancamiento antiguo (flecha).

\section{B1. Lesiones avulsivas crónicas}

Son el resultado de fuerzas repetitivas en las inserciones tendíneas o entesis. Afectan hueso y periostio. Tienden a ocurrir en los mismos sitios de fracturas avulsivas, aunque existen al menos tres formas ya descritas como entidad clínica: en la pierna (shint splint), en el muslo (thigh splint) y en el pubis (osteítis del pubis).

Por lo general no tienen representación en la Rx simple, sin embargo en niños y adolescentes, en especial deportistas, pueden manifestarse como irregularidad de la cortical y reacción perióstica planteando el diagnóstico diferencial con patología

\footnotetext{
* Nota del editor: Ver fractura de estrés de tibia en página 91.
}

tumoral o infecciosa en ausencia de antecedentes clínicos claros.

\section{B1a. Síndrome de estrés tibial interno o Shin Splint ${ }^{\star}$}

Las fracturas de estrés y el shin splint son causas conocidas de dolor en la pierna, especialmente en deportistas ${ }^{(3)}$. Ambos cuadros se caracterizan por dolor en la región medial que se acentúa con la actividad y desaparece con el reposo, interfiriendo con la actividad deportiva. Aunque ambas patologías corresponden a síndromes de sobreuso o lesiones avulsivas crónicas, son diferentes y puede variar su manejo, lo que hace importante su diagnóstico en etapa precoz. Se supone que corresponden a una respuesta diferente del esqueleto frente al estrés crónico y que una lesión podría preceder a la otra.

El síndrome de estrés tibial interno típicamente se presenta como dolor en el aspecto postero-medial de la tibia; origen del músculo sóleo, generalmente asociado a actividades deportivas que incluyen carreras sobre superficies duras. Sería debido a desgarro de las fibras de Sharpey en la interfase entre músculo y hueso (Figura 13), produciéndose periostitis por tracción y que afecta la fascia del sóleo $\mathrm{y}$ del tibial posterior.

La Rx simple es normal tanto en el shint splint como en las fracturas de estrés en etapa temprana, por lo que no es útil en el diagnóstico diferencial. El cintigrama óseo con difosfonatos marcados con Tc99m es un examen muy sensible pero inespecífico y muestra captación en ambos casos: en la fractura hay un foco captante. En el Shin splint puede haber una captación lineal longitudinal característica.

La RM es sensible y específica en el diagnóstico de ambas entidades y permite estudiar los tejidos blandos para descartar otras patologías. Se observa en el shin splint edema de disposición lineal en el aspecto antero y postero-medial de la tibia en relación al periostio de la misma (Figura 14).

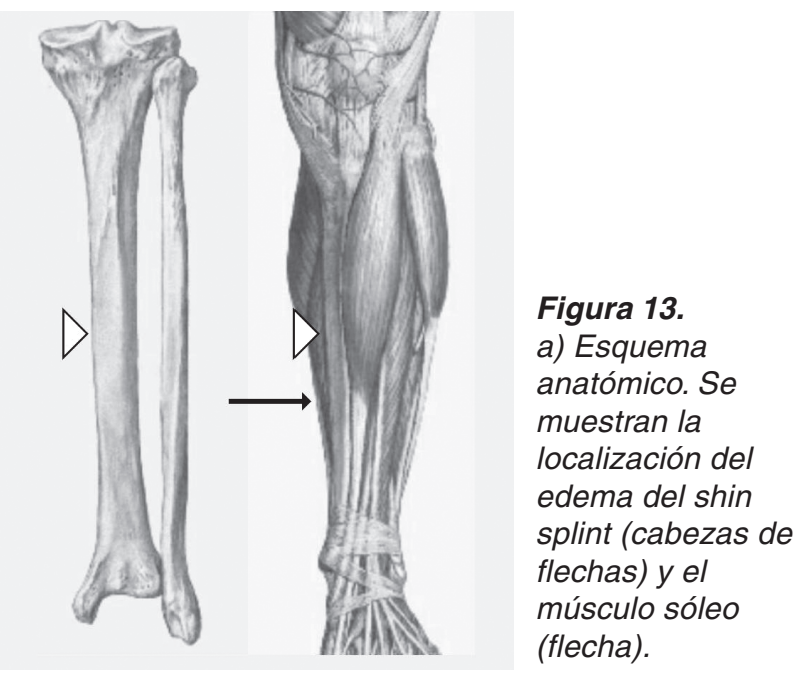



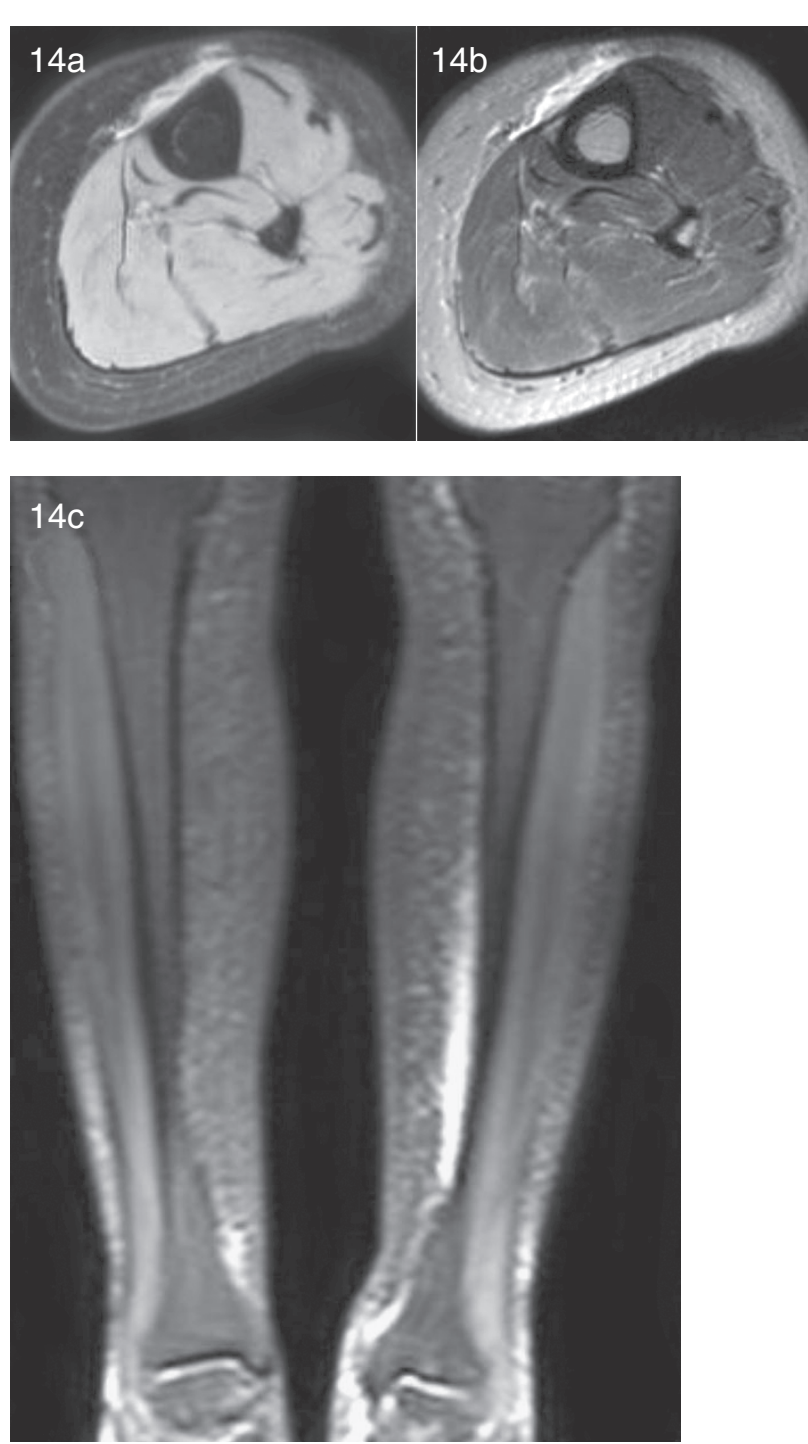

Figura 14. Paciente con síndrome de estrés tibial interno o shin splint: RM cortes axiales. a) DPFS. b) T2 .c) Coronal STIR. Muestran edema en disposición lineal en el aspecto antero-medial de la tibia izquierda.

B1b. Thigh Splint o Síndrome de avulsión del aductor: Fue descrito inicialmente en soldados, reclutas de la armada. Se ha ido conociendo en la medida que hay una mayor participación en deportes de la población en general, siendo lo común que el paciente consulte por dolor en el muslo, que aparece con la actividad física, referido a la región medial y proximal, sitio de inserción de los músculos aductores $^{(2)}$.

Los hallazgos imagenológicos son semiológicamente similares a los descritos para el Shin Splint.

B1c. Osteítis del pubis o Síndrome Gracilis: Es una condición dolorosa frecuente en atletas, también llamada lesión por estrés en el pubis. Descrito por primera vez en 1932 en saltadores de valla, posteriormente se ha observado en corredores de distancias largas y en otras actividades atléticas.

Corresponde a una osteítis traumática en el sitio de inserción del Gracilis y de los aductores en el pubis (Figuras 15 a). La clínica se caracteriza por dolor y sensibilidad perineal, en la cara medial del muslo y en la región inguinal, de aparición gradual y en relación con la actividad deportiva.

Radiológicamente puede encontrarse irregularidad de la cortical, reacción perióstica y microfragmentos óseos (Figuras 15 b). En el cintigrama óseo se observa captación en el área púbica, inespecífica, y en la RM alteración de señal de la médula ósea y en la inserción de los músculos aductores y gracilis. (Figura 16).
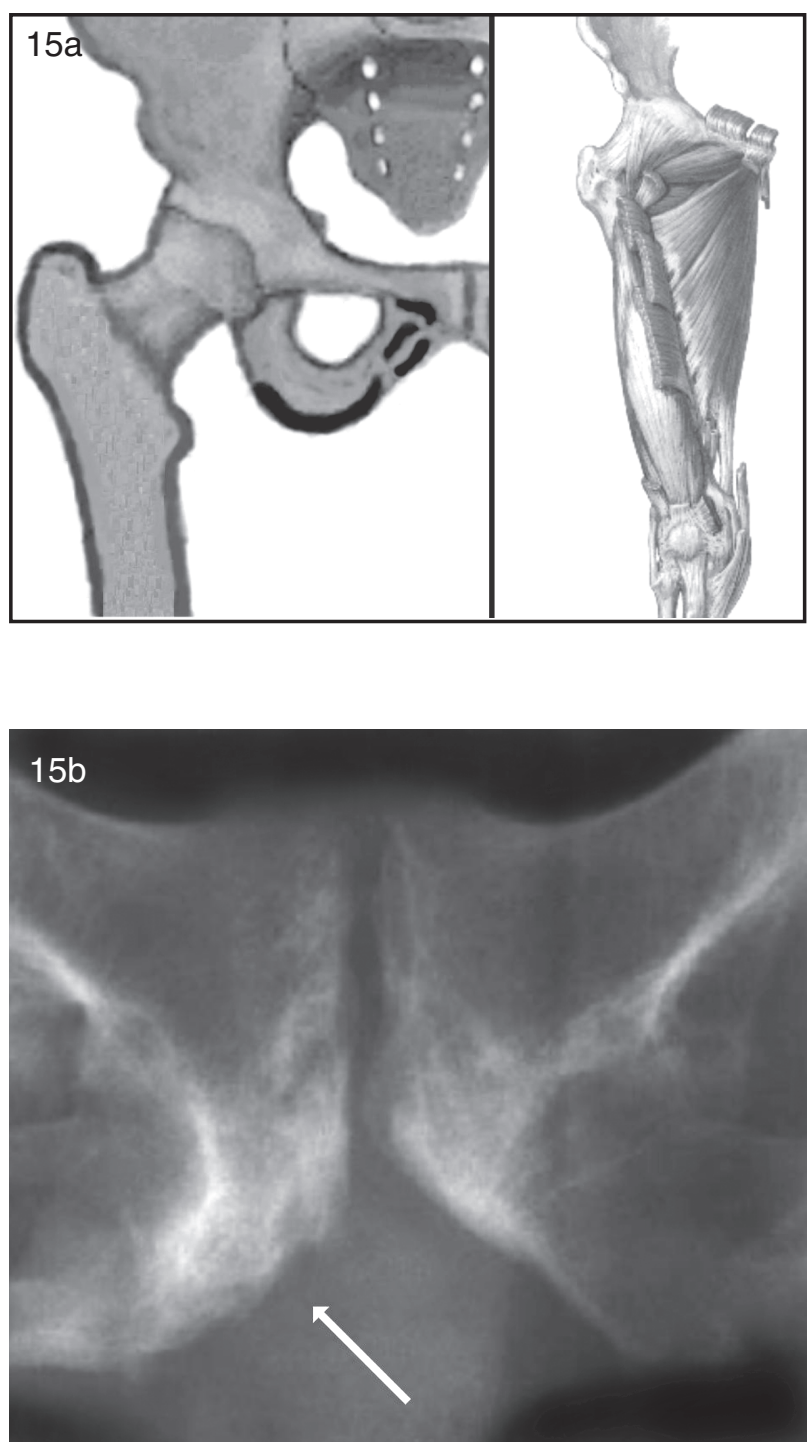

Figura 15 a, b. a) Esquema anatómico, mostrando las inserciones de músculos aductores y gracilis en pubis (en negro). b) $R x$ simple localizada de sínfisis pubiana, demostrando esclerosis e irregularidad de la cortical (flecha) compatible con osteitis del pubis o síndrome gracilis. 


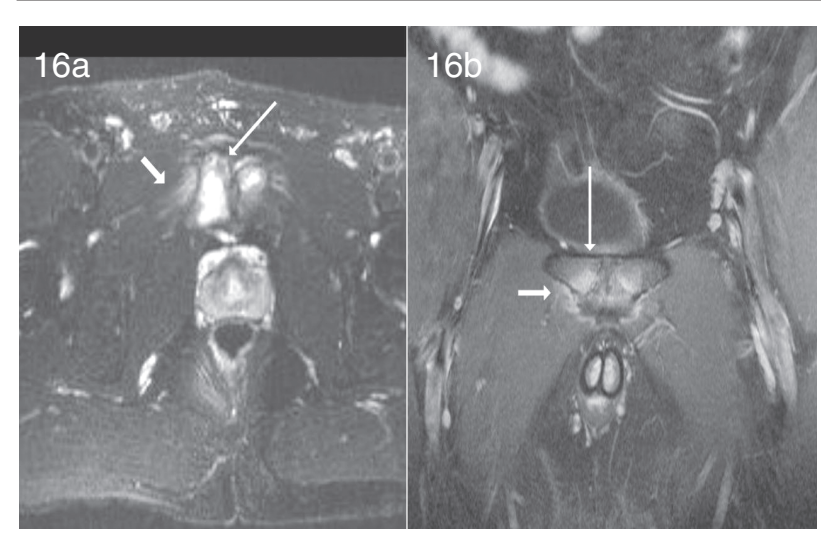

Figura 16 a, b. Deportista con pubalgia. a) Cortes STIR axial y b) Coronal. Muestran edema en ambos huesos pubianos (flechas finas) y en músculos aductores (flechas gruesas).

\section{B2. Fracturas de estrés}

Existen dos tipos: por fatiga que ocurre ante un estrés repetido sobre un hueso con resistencia elástica normal, y por insuficiencia que ocurre frente a un estrés fisiológico sobre un hueso con resistencia elástica anormal. Esta última no será incluida en esta revisión.

\section{B2a. Fracturas por fatiga}

Fueron descritas por primera vez en 1855 antes del descubrimiento de los rayos $X$.

Etiopatogenia: La patogénesis de las fracturas de estrés no está exactamente comprendida existiendo varias teorías para explicar su mecanismo.

Uno de los mayores roles del músculo es minimizar el estrés tensil sobre el hueso. Se ha demostrado que los tejidos blandos como tendones y ligamentos son estructuras estabilizadoras que también disminuyen la fuerza tensil sobre el hueso, aumentando la fuerza compresiva sobre el mismo. Debido a lo anterior las partes blandas descritas ayudan a prevenir las fracturas por fatiga. Cuando estas estructuras de soporte se fatigan, la fuerza tensil aumenta, resultando una mayor probabilidad de falla ósea.

De acuerdo a esto, la fatiga de los músculos en atletas mal acondicionados o entrenados en forma incorrecta crea un aumento del estrés tensil sobre el hueso resultando una fractura de estrés. La respuesta del hueso también es importante; es un tejido dinámico que requiere estrés para su desarrollo normal y sufre constante remodelación en respuesta a las fuerzas a que se encuentra sometido.

Inicialmente la remodelación ósea se manifiesta como actividad osteoclástica y reabsorción de hueso laminillar, que es reemplazado por hueso denso y fuerte. En una sobrecarga por estrés repetido, sin embargo, la acelerada remodelación provoca un desbalance entre la reabsorción y el reemplazo óseo llevando a un debilitamiento del mismo. El estrés continuo causa un mayor desequilibrio, llevando a fatiga ósea, lesión y fractura.

Otra explicación de la patogenia se relaciona con el aumento de la fuerza muscular. Bajo condiciones normales cuando un nuevo estrés es aplicado sobre el sistema músculo esquelético, el tono muscular se alcanza más rápidamente que la remodelación ósea. Esto conduce a un desbalance mecánico, con músculos que ejercen excesiva fuerza sobre el hueso, produciendo así la fatiga ósea. En la medida que el estrés aumenta hay una progresiva deformación hasta el punto de rango elástico, comenzando la deformación plástica y las microfracturas para llegar finalmente a la falla estructural.

Clínica: La sintomatología aparece después de periodos prolongados de actividades no acostumbradas, como carrera o marcha o por un cambio de actividad deportiva.

Característicamente hay dolor que aparece con la actividad o el ejercicio y cede con el reposo, antecedente muy útil para el diagnóstico diferencial con otras entidades, con aspecto radiológico similar como una lesión tumoral, en que el dolor persiste durante el reposo.

Pueden ocurrir en cualquier hueso, aunque son mucho más frecuentes en las extremidades inferiores. Un $73 \%$ del total de las fracturas por estrés ocurre en la tibia.

La localización se asocia con determinadas actividades: de esta forma las fracturas de pierna (tibia y peroné) se observan en maratonistas, las de fémur en bailarinas, etc. Para hacer el diagnóstico es muy importante tener un alto grado de sospecha.

Una vez hecho el diagnóstico es importante clasificarla como: lesión crítica, menos crítica o no crítica, dependiendo de su localización, ya que el tratamiento y pronóstico son diferentes. De alto riesgo son: cuello femoral, tibia media anterior, navicular y sesamoideos. De riesgo medio son: diáfisis femoral, diáfisis tibial póstero-medial, maléolo-medial, y diáfisis proximal del $\mathrm{V}$ metatarsiano. De bajo riesgo: peroné distal, calcáneo, II, III, IV y V metatarsiano distal ${ }^{(7)}$.

Estudio por imágenes: La Rx simple no es útil en la etapa precoz e inicialmente es normal y se hace positiva en un período que puede variar entre dos semanas y tres meses. La evolución muestra reacción perióstica, formación de callo o línea de fractura. Su sensibilidad para detectar lesiones precozmente es de un $15 \%{ }^{(7,8)}$. El seguimiento radiológico puede demostrar el diagnóstico en hasta un $50 \%$ de los casos.

La RM es una excelente herramienta diagnóstica en estadios precoces (Figuras 17,18). Tiene una sensibilidad similar al cintigrama y su 


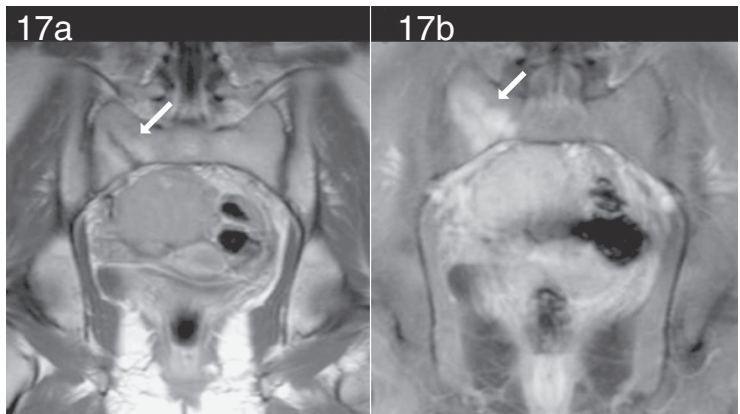

Figura 17 a-b. Deportista con dolor pelviano cuya $R x$ simple AP de sacro era normal. a) RM cortes Coronal T1 y b) STIR. Muestran fractura vertical en alerón sacro derecho compatible con fractura de estrés (flechas).

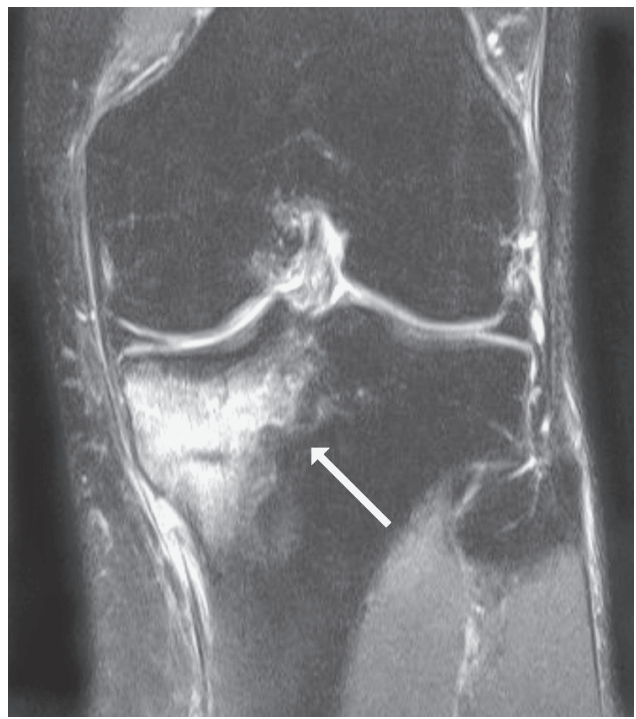

Figura 18. Maratonista que consulta por dolor de rodilla. La Rx simple de rodilla no demostró lesión ósea. La RM en secuencia DPFS muestra importante edema tibial con fractura de estrés (flecha).

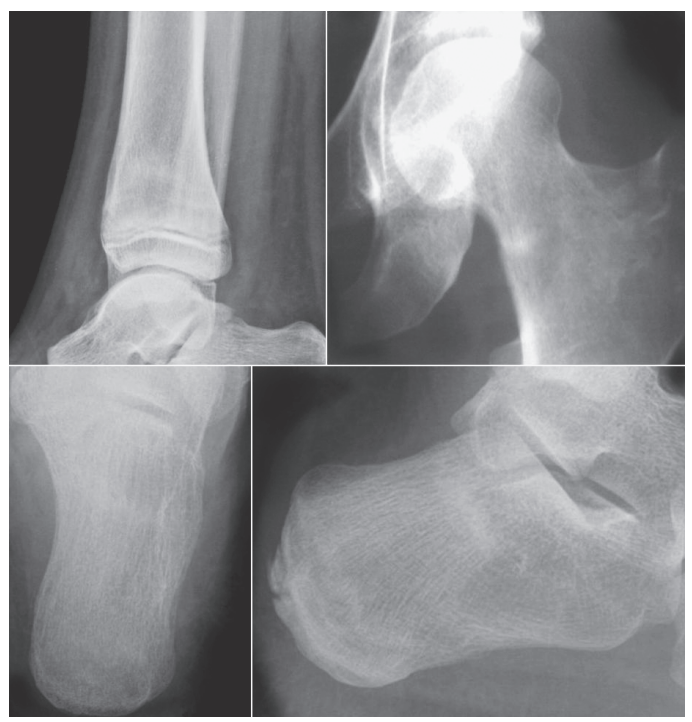

Figura 19. Rxs simples lateral de tobillo, AP cadera, axial y lateral de calcáneo que muestran fracturas de estrés como líneas densas perpendiculares a las trabéculas (flechas). especificidad es mayor. Muestra, además, los tejidos blandos y permite hacer el diagnóstico diferencial con otras causas de dolor.

En zonas de predominio medular, como ocurre en calcáneo y cuello femoral, la Rx muestra una línea de esclerosis perpendicular a las trabéculas (Figura 19). En el hueso cortical, en cambio, hay típicamente una reacción perióstica (callo), una línea cortical de fractura o ambas (Figura 20).

Tanto la reabsorción como la formación de hueso son características de una fractura por estrés en etapa temprana. Esto se manifiesta como hiperemia local y edema, detectados con gran sensibilidad por la RM tanto en el periostio como en el hueso medular y músculos. También es posible detectar la línea de fractura que es perpendicular a la cortical y en dirección al canal medular ${ }^{(7,8)}$ (Figuras 21-23). Existen algunas formas de presentación menos frecuentes, como las fracturas longitudinales que pueden afectar a huesos largos ${ }^{(5)}$.

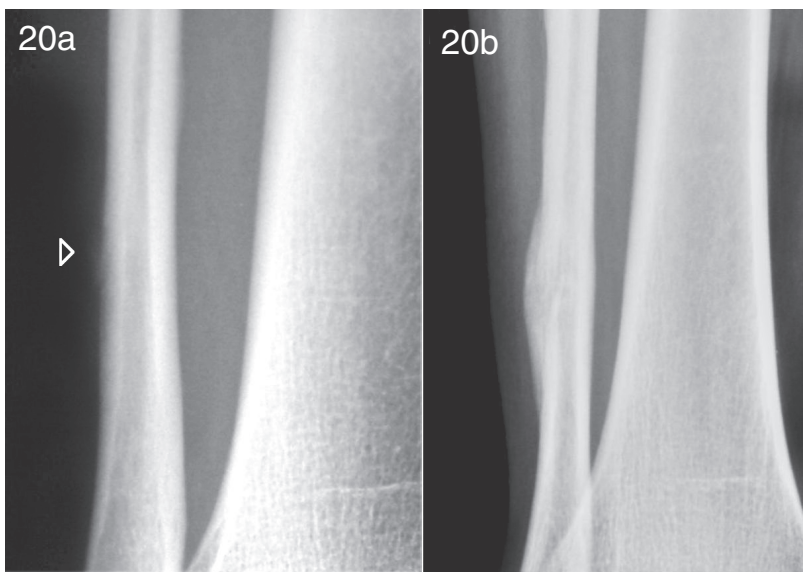

Figura 20 a, b. Deportista con dolor en pierna derecha. a) $R x$ simple AP localizada y b) Control a las 3 semanas. Muestra fractura de estrés con compromiso cortical (punta de flecha) y desarrollo de callo óseo perióstico.

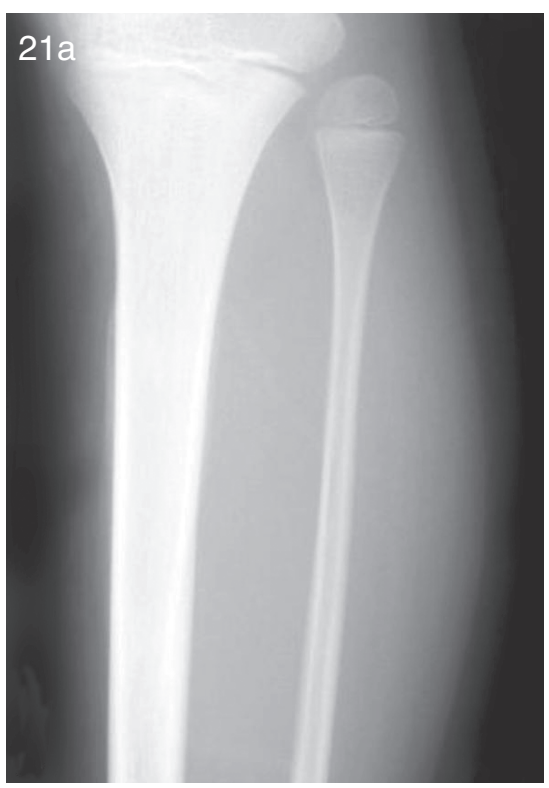



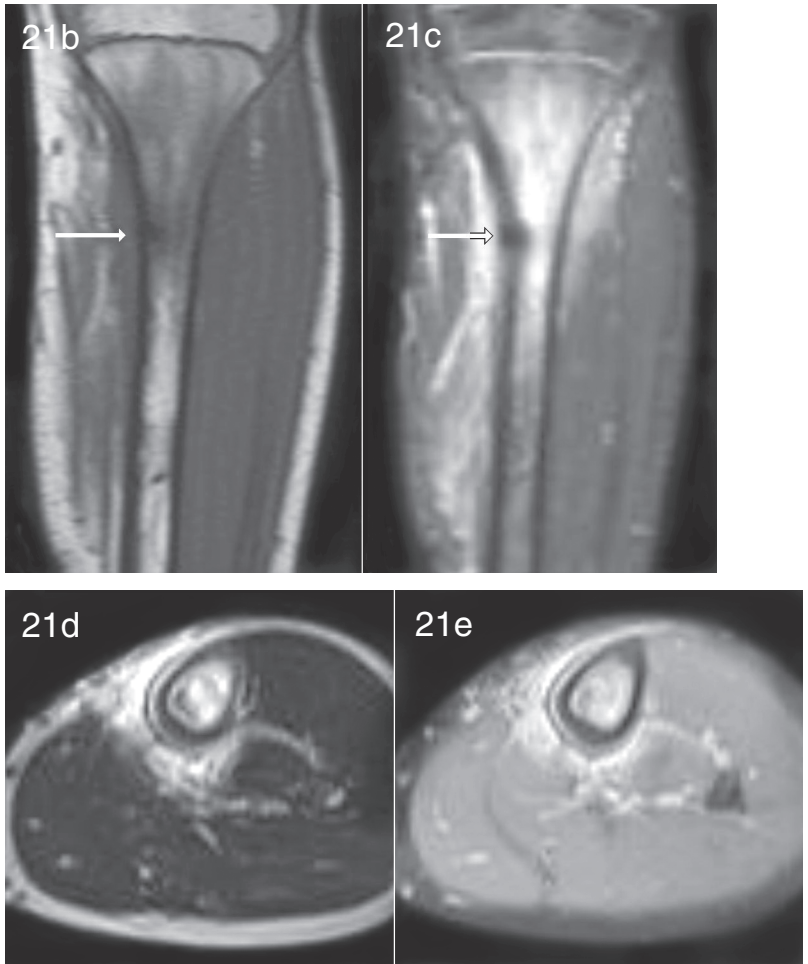

Figura 21 a-e. Niño con dolor en pierna izquierda: a) $R x$ simple AP de pierna muestra una tenue reacción perióstica laminar en la tibia. Se plantea el diagnóstico diferencial con lesión tumoral. RM b) Cortes coronal T1. c) STIR. Axiales T2 (d) y DPFS (e) demuestran importante edema medular y de las partes blandas, con pequeño rasgo de fractura (flechas en $b, c)$.
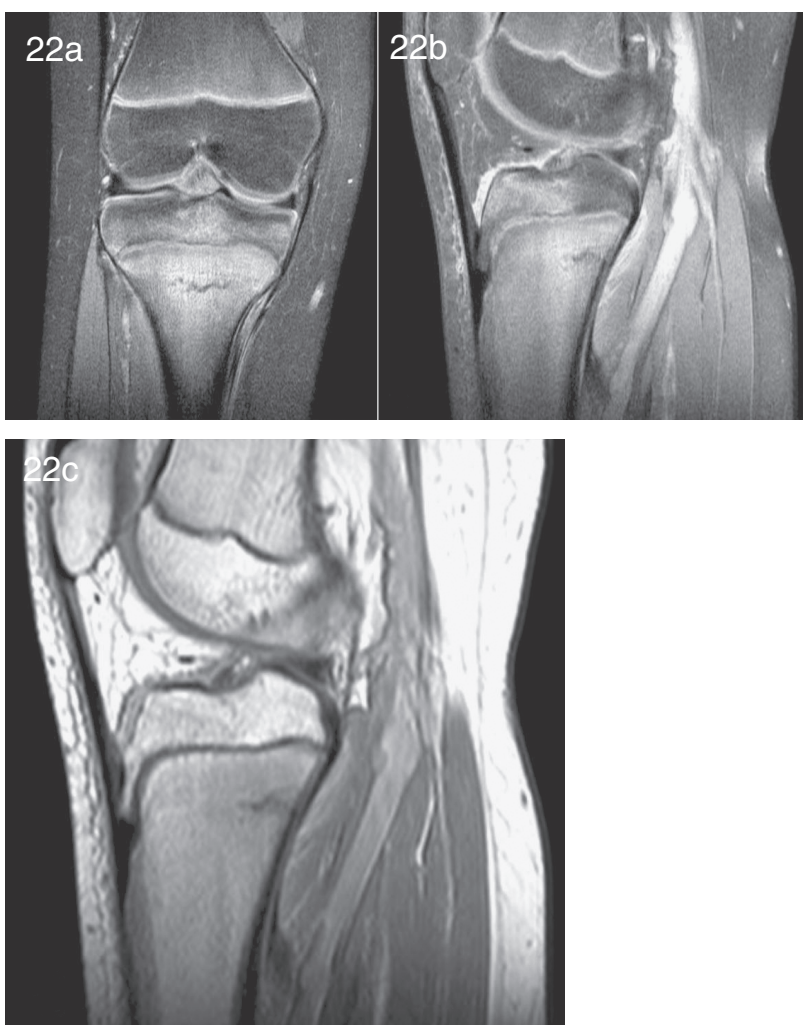

Figura 22 a-c. Niño con dolor de rodilla: a) Cortes coronal DPFS y b) Sagitales DPFS y c) DP. Muestran edema en metafisis tibial y rasgo de fractura transversal.

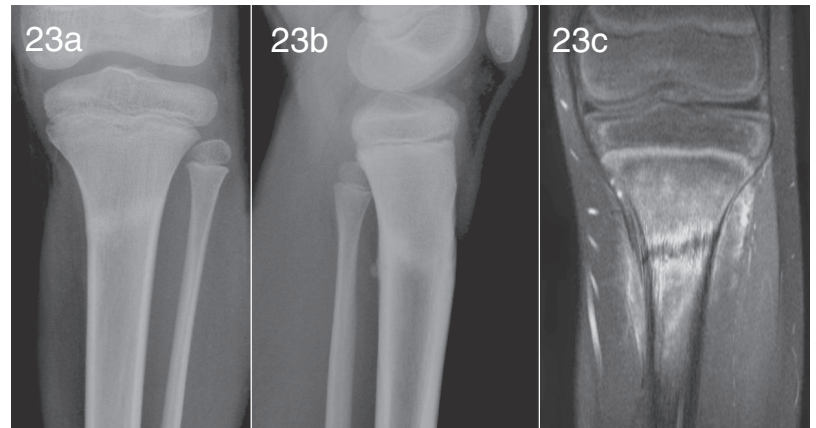

Figura 23 a-c. Niño con dolor de pierna de larga data: a) Rxs simples AP y b) Lateral de pierna. Muestran fractura de estrés en tibia con proliferación ósea dorsal. c) Corte coronal DPFS. Confirma fractura con edema óseo adyacente.

El cintigrama era el estándar de referencia hasta la aparición de la RM. Es una herramienta que sigue siendo útil por su alta sensibilidad; sin embargo su especificidad es baja. Las imágenes más típicas son un área de intensa captación en el foco de fractura que presenta una gran actividad osteoblástica (Figura 24).

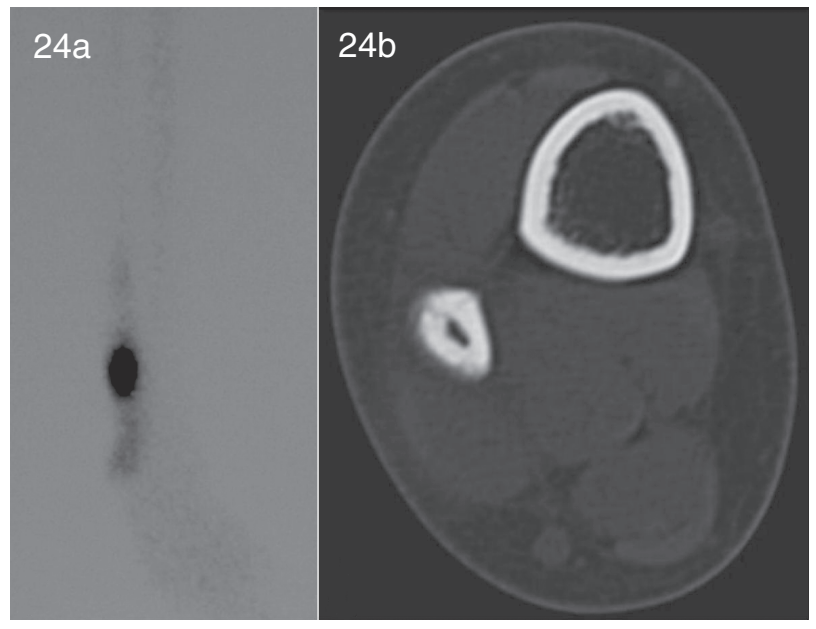

Figura 24 a, b. Paciente con fractura de estrés de peroné: a) Cintigrama óseo, demuestra un foco de intensa captación. b) Corte tomográfico, confirma rasgo de fractura.

La tomografía computada (TC) tiene escasas indicaciones: no se utiliza como examen único o inicial. Es útil para hacer el diagnóstico diferencial especialmente con el osteoma osteoide donde tiene alta especificidad diagnóstica porque demuestra la presencia de un nido (Figura 25). Puede ser útil para valorar la evolución de una fractura (Figura 26) en un sitio anatómico complejo en el cual la Rx simple no demuestra con claridad el callo óseo, como ocurre por ejemplo en la pelvis, el tarso o la columna.

Diagnóstico diferencial: Los diagnósticos diferenciales incluyen: osteoma osteoide; osteomielitis crónica esclerosante; osteomalacia; metástasis óseas; osteosarcoma; sarcoma de Ewing. 


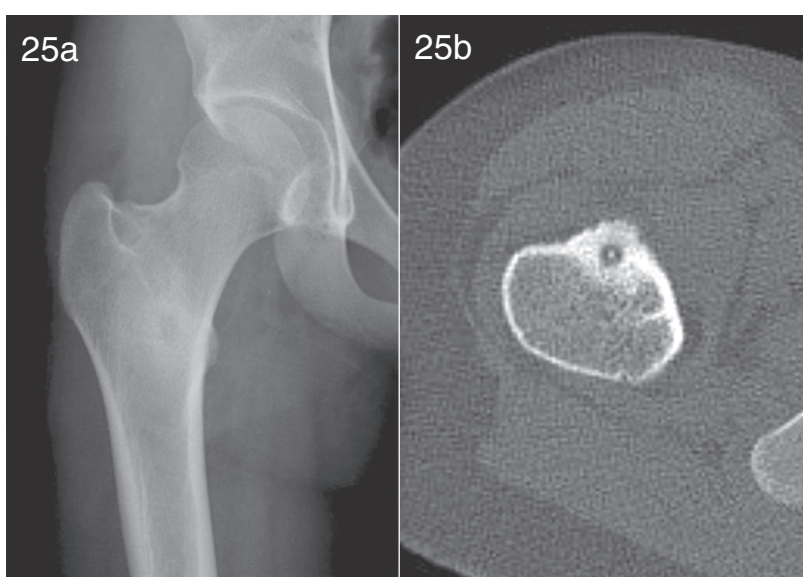

Figura 25 a, b. Osteoma osteoide que plantea el diagnóstico diferencial con fractura de estrés. La tomografía computada muestra importante reacción esclerótica con presencia de nido central. a) $R x$ y b) TC.
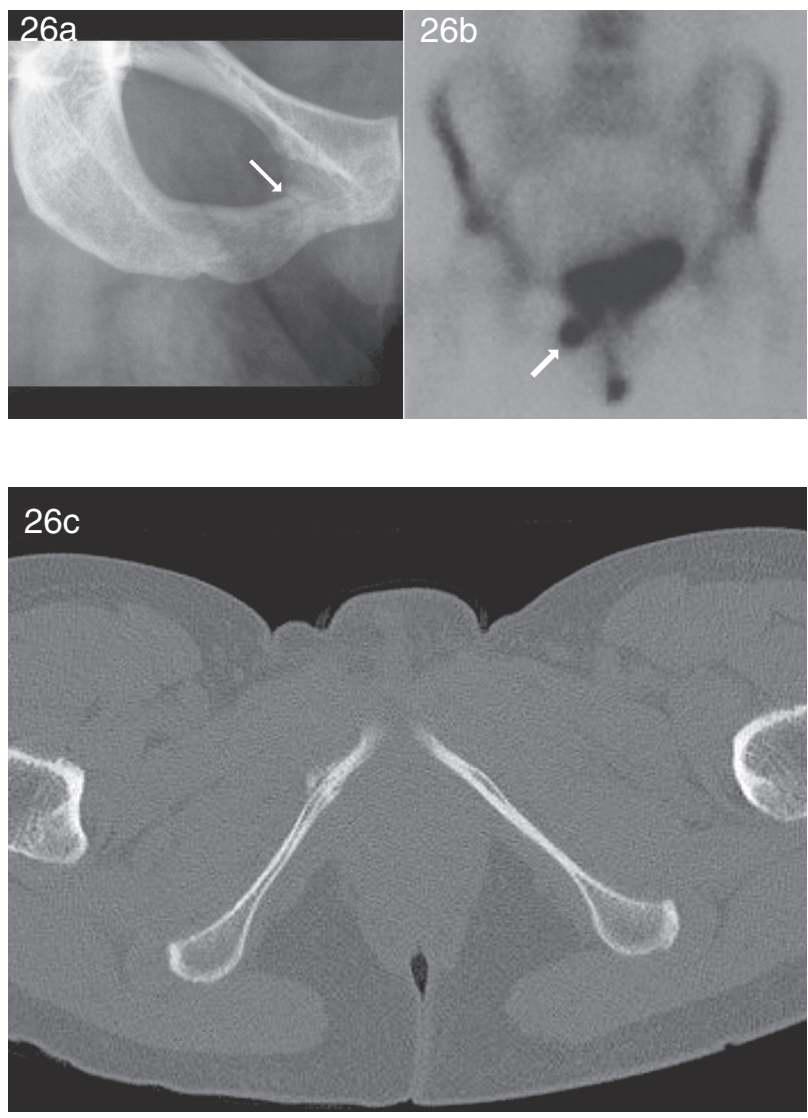

Figura 26. Deportista con dolor pelviano secundario a su actividad. Fractura de estrés en la rama isquiopubiana (flechas): a) Rx simple. b) Cintigrama óseo con Tc99m MDP. c)TC efectuada para evaluar la formación de callo óseo.
El osteoma osteoide puede presentar un aspecto radiológico similar a una fractura por estrés en etapa avanzada. Ambas entidades consultan por dolor, aunque clínicamente tienen diferente comportamiento. El diagnóstico diferencial imagenológico puede establecerse con TC.

La infección y patología metabólica no deberían constituir un problema ya que en ambos casos debieran existir antecedentes clínicos o exámenes de laboratorio que permitan una mejor orientación inicial.

Las patologías neoplásicas son realmente las que constituyen un desafío en la práctica diaria y pueden constituir un problema diagnóstico; sin embargo, a pesar que pueden tener hallazgos imagenológicos muy similares, tienen un comportamiento clínico diferente.

Frente a la duda diagnóstica entre fractura por estrés y alguna de estas entidades, pensamos que sería importante antes de realizar una biopsia controlar radiológicamente en dos o tres semanas después de inmovilización, debido a que una fractura por estrés evidenciara cambios en la imagen radiológica determinados por la formación de callo óseo. El dolor además desaparecerá con el reposo.

\section{Bibliografía}

1. Donnelly LF, Bisset GS, Helms CA, Squire DL. Chronic avulsive injuries of childhood. Skeletal Radiol 1999; 28:138-144.

2. Anderson MW, Kaplan PA, Dussault RG. Adductor Insertion Avulsion Syndrome (Thigh Splints): Spectrum of MR Imaging Features. AJR 2001; 177, September

3. Yoshimitsu Aoki, Kazunori Yasuda, Harukazu Tohyama et al. Magnetic Resonance Imaging in Stress Fractures and Shin Splints Clinical Orthopedics and related research 2004. 421: 260-267.

4. Anderson J O, Johnston R, O'Donnell L. S. Steinbach MR. Imaging of Sports-Related Pseudotumor in Children: MidFemoral Diaphyseal Periostitis at Insertion Site of Adductor Musculatures. E. AJR:176, May 2001.

5. Hilary R. Umans Jeremy J. Kaye Longitudinal stress fractures of the tibia: diagnosis by magnetic resonance imaging Skeletal Radiol 1996; 25:319-324.

6. Sanders TG, Medynski MA, Feller JF, Lawhorn KW. Bone Contusion Patterns of the Knee at MR Imaging: Footprint of the Mechanism of Injury RadioGraphics 2000; 20:S135-S151.

7. Bergman G, Fredericson M. MR Imaging of stress reactions, muscle injuries, and other overuse injuries in runners. Magn Reson Imaging Clin N Am 1999; 7: 1.

8. Spitz DL, Newberg AH. Imaging of stress fractures in the athlete. Magn Reson Imaging Clin N Am 2003; 11:323-339. 